\title{
Different Educational Approaches in Design Studio
}

\author{
Begüm Erçevik Sönmez ${ }^{1 \odot}$ \\ ${ }^{1}$ Asst. Prof. Dr., Faculty of Architecture, Yeditepe University, İstanbul, Turkey. (Principal contact for editorial correspondence.) \\ Email: begumer@gmail.com; begum.ercevik@yeditepe.edu.tr
}

\begin{abstract}
Purpose

In the architectural design studio education, series of approaches, such as vertical, traditional, constructivist or virtual, are executed. In this research, an experiment was executed with the aim of revealing the effects of different architectural design studio approaches through the comparisons of student assessments. The study was based on the research question related to which of the approaches applied in the architectural design studio is the successful and productive one. The research hypothesized that in architectural design education, the independent design studio approach is more successful than the controlled studio approach.
\end{abstract}

\section{Design/Methodology/Approach}

Two different approaches were compared. The independent studio approach, in which students studied freely in studio milieu, was applied full-time 9 hours a week session in the Fall Semester. The controlled design studio approach, executed as two half days per week in the Spring Semester, proceeded with the desk critiques in a group supervised by an instructor. At the end of each semester a questionnaire that evaluated each design studio approach was conducted to 44 third-year design studio students.

\section{Findings}

The controlled design studio appeared to be a more dynamic approach in which following on the critiques of the instructor was ease. The group instructor provided sufficient time to all students for the critiques, whereas in the independent studio approach, the interaction between the instructors and the students was weak. Following up the critiques of different instructors was a difficult process. The controlled design studio was found to be more successful than the independent studio approach. The hypothesis of the research is not confirmed.

\section{Research Limitations/Implications}

The most important limitation of this study was that the comparisons were only made through the students' assessments, and the instructors were not included in the research.

\section{Social/Practical Implications}

The meetings with the instructors should be arranged twice a week to keep students under control of instructors, and to prevent the reluctance of the students in the design studio.

\section{Originality/Value}

This study makes a difference in comparing studio approaches and contributes to the discussions on architectural design studio education. 


\section{INTRODUCTION}

Design, which is a process of analysing, synthesizing and evaluating, is full of repetitive activities that continue between the definition of a problem and its solution. The number of possible solutions to a design problem is infinite and it changes according to the environment it exists in (Ibrahim \& Utaberta, 2011).

The design studio is the essence of architectural education. The architectural design studio, which focuses on "learning by doing", is a sample of a collaborative, multi-sensory, experimental, student-centred, and problem-based training medium. Design studio ensures architectural students all the specialty and knowledge required to generate innovative and imaginative design solutions. Its main purpose is to improve students' imagination in design, enable them to provide creative approaches to design problems and introduce them to express their ideas through different techniques such as drawings, physical models, computer models, photographs or videos (Ibrahim \& Utaberta, 2011). The design studio is the sole process in which the practices for creating an architectural project are experienced by the students, and it prepares them for real-life situations beyond their formal studies.

In the design studio, which is conventional in each of the schools that educate in architecture, the students tackle a design problem in a group of ten to twelve students, supervised by a tutor or a professor. At the beginning of the architectural design studio, the instructors may inform the students about the design problem, objectives, expectations, general method, and assessment measures of the final products.

Each design studio generally requires the creation of architectural space and volume, the selection of the accurate material and structural system, and the presentations in drawings, perspectives and mock-ups. During the semester, instructors negotiate with the students individually about their design once or twice in a week each consisting of at least four-hour blocks. The desk critiques are the appointments with the students discussing their attitudes, their opinions, their progress, their products, and their challenges about the given design problem. Then, at the end of the semester, the final products are assessed in a final jury traditionally composed of the instructors or master designers.

On the other hand, some problems of a traditional design studio can be outlined as follows: The education is an instructor-centred process. The instructors demonstrate to students what to do and students execute what they are told. Besides, the number of students to be supervised per instructor is quite high. The architectural approaches of the famous architects, the instructors, or more senior classmates are imitated by the students. They are reluctant to take initiative and responsibility in design and expect constant affirmation. In addition, the studio is focused on the end product rather than the design process. The collaboration of the students is limited due to the lack of enough group work to enhance students' creativity (Kurt, 2009; Ciravoğlu, 2014). 
Kurt (2009) compared the traditional studio with the constructivist one in general and recommended the conversion of the traditional design studio to the constructivist one to reduce such problems of the traditional design studio and defined the general properties of the constructivist studio as follows: The design process is significant and it does not focus on the resulting design. It is a spread studio in which students from different grades are trained. Collaboration and exchanging of views and ideas are significant in the design process. Besides, in constructivist studios, desk critiques and/or screen critiques are also significant for pursuing the design process of the students as well as in traditional studios.

Ciravoğlu (2014) shared a new design studio method in architectural education to cope with the problems of the traditional design studio mentioned above. In this new teaching method, every week, a single critique between a student and an instructor, and also multiple critiques with all of the studio instructors were conducted. According to Ciravoğlu (2014), this new teaching method gave more responsibility to the student and the project developed with the different ideas of different instructors. Conversely, critiques from different instructors did not match each other and the necessary environment for brainstorming by the whole students and instructors could not be actualized. Even though this new method was found mostly constructive by the instructors, students were not ready for it. Moreover, the cultural codes such as lifestyle, rules, daily routines, personal identity, experience, beliefs, age, gender, family type, the area of residence, and level of education should be considered as significant determinants in developing a new design studio method. Önal and Turgut (2017) indicated that the difference in students' design studio products was due to the distinctness in their cultural schemes. The cultural schemes are the encoding, storage, and interpretation of cultural information and cultural experiences of the individual through cognitive processes. Cultural experiences are related to the cultural components that affect the individuals' perception, learning, and decision-making processes by constituting normative concepts such as worldview, lifestyle, and habits. These normative concepts are coded and stored and constitute cultural schemes. These entire processes convert to a series of spatial behavioural systems that reveal design action. In this way, the cultural schemes of the individual affect the ability of his/her learning and designing. The design knowledge that is needed in the design process is directly proportional to the cultural scheme of the designer. Hence, individual cultural components, such as cultural values and students' abilities of cognition must be admitted as a significant part of the studio approach to educate the students as designers.

Akalın and Sezal (2009) mention the vertical design studio approach which was conducted at Gazi University Department of Architecture. Students are independent to choose one of the six design studio ateliers which have different conceptual formation and have an equal number of architectural students from different grades. It is a studio-based learning 
approach in which projects on the main theme are determined starting from less complex projects for freshmen and more difficult ones for senior classes. Preparation, conceptual sketches and models, drafts and concrete models, and final (full drawings, concrete models) are the four phases in each atelier. Akalın and Sezal (2009) mention that the vertical design studio is a dynamic, flexible and free medium where academic, interdisciplinary and professional practices are executed, and students from different grades can be trained together. Likewise, Ketizmen (2003) stated that in a design studio system where design problems with different complexity levels were carried out simultaneously, students could exchange ideas with the students from higher grades and gain different perspectives, besides the assistance of the instructor.

On the other hand, some disadvantages of the vertical design studio can also be mentioned. According to K. A. Youssef (2014), the vertical design studio is suitable for training groups with a small number of design students whereas the instructors need to make more efforts due to the concentration problems of students within the group or/and between groups. Besides, hard collaboration is strongly recommended. The rapid development of experienced senior students during the design process motivates some students and helps the design problems to progress. However, this rapid progress in design causes motivation losses in some students because of a feeling of lagging behind. Besides, during the preliminary preparation of the design studio, there may be disagreements among instructors regarding the design problems, space size and detail scale to be given to students at different levels due to the lack of a unified curriculum (Adıgüzel Özbek, Yücesan, Melikoğlu Eke \& Özar, 2018).

Ketizmen (2003) examined the design studio methods applied at Anadolu University Department of Architecture under six headings: the theoretical knowledge transfer method in which visual materials are transferred to the students through seminars and conferences; criticism method including the juries, group critiques, and individual critiques; sample project method in which the architectural solutions or suggestions belonging to professionals are examined as examples; applicationoriented design method which allows the student to practice with mockups or computer-aided three-dimensional modelling from the beginnings of the design process; problem-solving method in which the students come up with the appropriate solutions to a design problem in and of itself; and individual study method which aims to improve the student's ability to generate individual solutions to a design problem after all the exercises are carried out together with the instructor in the design studio environment.

Instead of using existing templates, Paker Kahvecioğlu (2007) suggests a studio curriculum that provides a medium for creating new ideas and enables creativity to be enhanced through different types of activities such as collective group works, workshops, work-trips, and one-day charrettes, or competitions. Thus, the students experience the design 
activities and produce new ideas rather than being passive learners and the design studio becomes an intellectual, interactive, transitive, sharing, participatory, and communicating medium besides games and entertainment.

Afacan (2012) focused on the contributions of group work in an architectural design studio and performed an analysis from the two perspectives of the learning process and the process of working with others. Regarding the learning process, she was found out that group work was an effective way of learning. Group work allows students to be informed about different ideas with brainstorming and to be able to approach the design problems from different viewpoints. Experiencing different ideas of design enhanced their creativity. Furthermore, working within a group improved the relationship of the students with other people. Ulusoy (1999) traced freshman students' visual and verbal abilities via their design studio performances. The students with verbal or graphic abilities reflected this distinctness in their abilities onto their designs and their cognizance of design in terms of graphic or verbal thinking. Students with graphic abilities can be better at expressing themselves visually than verbally.

Niraj Verma (1997), in the empirical research, questioned the benefits of design studio training or professional experience in understanding the design theory and found out that the students' knowledge of design theory was higher when the students had prior design studio experience or professional work-experience as compared to when they did not. The second interpretation was that design studio is crucial for freshmen architecture students and theoretical education may be more appropriate for the students who have some experience in the design such as senior classes or grad ones.

Demirbaş and Demirkan (2003) focused on the architectural design process through learning styles that were "accommodating (learning by experiencing and doing)", "diverging (learning by experiencing and reflecting)", "converging (learning by thinking and doing)" and "assimilating (learning by thinking and reflecting)", and reviewed the effects of learning style preferences on the performance of design students. Most of the freshman students learning styles were converging and assimilating. The research was concluded with the claim that different stages of design education should be associated with different learning styles. The findings of Demirbaş and Demirkan (2007) also support their previous research that during design education, students use all the learning phases. During the design process, a variety of learning experiences that emphasize different learning styles must be provided to design students. Design groups that have students with different learning styles can be arranged. For instance, diverging learners are the most creative ones, and they bring various ideas and ways of problem-solving to the studio medium. Besides, converging learners are successful in design performance. On the other hand, Kvan and Yunyan (2005) indicated that the formulation of the design program (ill-divine or 
well-divine), presentation requirements (drawing, model or oral presentation) and duration of design studio could disadvantage certain learning styles.

Oh, Ishizaki, Gross and Yi-Luen Do (2013) highlight that the student learning may be influenced by the interaction between the instructor and students. Since critiquing is essential for the relationship between the instructor and students, Oh et.al (2013) present some ways of providing effective feedback to design students. The instructor requires choosing the appropriate critiquing types such as desk critiques, group critiques, interim review, final review, and informal interaction according to the students' levels of knowledge, the students' grade as well as the project phases. Multiple critiquing types may be used in a single studio course. For instance, for freshmen architecture students, the instructor can use more advisor critiques in the early phases and can be more facilitator later in the semester. Besides, Uluoğlu (2000) underlines the significance of effective communication between the instructors and the students in architectural design education and characterizes the studio critiques as indispensable tools for enhancing the students in producing their design ideas. Group critiques are substantial in indicating the typical issues and problems of design to the students, and juries are crucial for periodical assessments of the overall designs.

As mentioned before, instructor-student and student-student discussions are the most significant sources of knowledge for students in design studio training. Since such discussions and communications are executed during course hours and in the studio medium, they can have some time and space limitations. Moreover, some students may prefer not to share their knowledge or share some part of it so that they can be more successful in design than their peers. Wu, Lin, Wen, Perng, and Hsu (2016) proposed an effective architectural design knowledge management system which can enable students to share their works, communicate with their instructors or peers, post their design drafts during their design process, offer critiques on each other's works, and offer comments from their instructors. This proposed system can help to improve the communication between instructor-student and studentstudent, effectively enhance the students' learning efficiency, and consequently improve their learning quality.

Architectural design studio education is being restated by the developments in design computing and the use of digital media in the last decades. Reffat (2007) introduces two approaches for architectural design studio education using information and communication technology which includes a paperless design studio, and a collaborative virtual design studio. The approach of paperless design studio encourages the usage of high-end software such as Alias/Wave front, Softimage, and Maya which provide numerous new design ideas to the students, and the opportunity to test climatic changes, colour and texture schemes. Besides, a virtual design studio approach enriches the architectural experience with cross-cultural studios in collaboration with 
other schools of architecture by using video conferencing. Furthermore, Kurt (2011) indicates that architectural design studio should comprise the use of computer-aided design programs, virtual design studios, digital studios and internet applications throughout the design process to encourage the students to be interactive, process-oriented, open-minded, initiative, self-controlling, participatory, and collaborative.

Demirkan and Afacan (2012) explored design studio education from a different viewpoint by measuring the creativity of the products and mentioned that as the instructors analyse a design product, the characteristics of novelty and influence, the amount of elaboration, and lastly, qualities of design as rhythm, repetition, unity, and order are the factors that affect the instructors. Mutlu Danacl (2015) specified that creativity is a phenomenon in the design studio. Giving the necessary knowledge to the student at the right time, referring the student to research, providing integration between theoretical and applied courses, and using theoretical knowledge in the application of design will encourage a certain amount of creativity.

It has been observed from the literature review mentioned above that in architectural design studio education series of approaches, such as vertical, traditional, constructivist or virtual, are executed. However, the effects of the distinctive design studio approaches on students learning, design process and the final product are being unknown. Thus, the research was based on the following research questions mentioned below:

- Which approach applied in the architectural design studio is the successful and productive one?

- What are the positive or negative aspects of the design studio approaches that differ from the others?

- How can weekly architectural design studio hours be organized to enhance student achievement?

- What are the suggestions to the instructors for the execution of the design studio that can influence student achievement?

In this study, an experiment was executed with the aim of revealing the effects of different architectural design studio approaches on the design studio education through the comparison of student assessments. This study makes a difference in comparing studio approaches and contributes to the discussions on architectural design studio education. Besides, the fact that the discussions were conducted only through student assessment constitutes the limitation of the study.

\section{THE AIMS OF THE STUDY}

The aims of this study can be listed as follows:

- To compare different approaches in architectural design studio education through student assessments.

- $\quad$ To explore the positive and negative aspects of different approaches applied in architectural design studio education; 
- $\quad$ To develop an appropriate design studio approach to increase students' design studio achievements;

- $\quad$ To generate directory suggestions for instructors or tutors;

In this research, two different approaches applied in architectural design studio were compared: independent design studio approach and controlled design studio approach. The independent studio approach was applied as full-time 9 hours a week session, in which students studied freely in a design studio milieu without engaging to a specific group of students and an instructor. In this approach, the students were not obligated to get critiques from any of the instructors. Conversely, the controlled design studio approach, applied as two half days ( $4+5$ hours) per week, proceeded with the desk critiques in a group of 12 to 15 students, supervised by an instructor or a professor. In this approach, the students were obligated to present their work and get individual critiques from their instructor.

The controlled design studio approach has similar features as the traditional design studio; however, the independent design studio approach is an experimental approach envisaged by the researcher and the studio instructors. In the infancy of the research, the advantages and the disadvantages related to the independent design studio, which are detailed in the discussion section, were revealed by the researcher.

The hypothesis of the study was constituted as follows:

H: In architectural design education, the independent design studio approach is more successful than the controlled studio approach.

\section{PROCEDURE}

This research examined two different design studio approaches, experienced by third-year design studio students from the Department of Interior Architecture and Environmental Design at a university in Istanbul. The independent design studio approach was executed in the Fall Semester while the controlled studio approach was executed in the Spring Semester.

Within the scope of Design Studio III in the Fall Semester, the students were given the task of designing a medical clinic such as a dentist, veterinarian, and aesthetic centre. The design problem and the design area which was selected for the organization of the medical clinic were the same for all the students. Design Studio III was held with the participation of 44 students, four instructors, and one research assistant. The total education time in a semester was 14 weeks, and the design studio was executed full-time 9-hours a week. The studio hours proceeded with the students practicing in two ateliers which had similar physical properties and were located side by side while the instructors gave critics alternately in both ateliers when requested by the students. Two interim reviews and one final jury were held to evaluate the products. At the end of the final jury assessment of the Design Studio III in the Fall Semester, a questionnaire that evaluated the independent 
design studio approach was conducted to 44 third-year students. It was directed to all the students simultaneously on a single day.

Within the scope of Design Studio IV in the Spring Semester, the students were given the task of designing a boutique hotel near the Bosporus. The design problem and the design area which was selected for the organization of the boutique hotel were the same for all the students. Design Studio IV was held with the participation of the same 44 students, the same four instructors, and the same research assistant as the Design Studio III held in the Fall Semester. The total education time in a semester was 14 weeks, and the design studio was executed two half days ( $4+5$ hours) per week. The studio hours proceeded with the group critiques in two ateliers which had similar physical properties and were located side by side. Two interim reviews and one final jury were held to evaluate the products. The method of the interim reviews and the final jury were the same for both of the approaches. The same questionnaire was directed to the same students at the end of the final jury assessment of Design Studio IV in the Spring Semester to evaluate the controlled design studio experience. The questionnaire was conducted to all third-year students simultaneously on a single day.

Initially, the students were informed in detail by the researcher about the aims of the study, privacy, and withdrawal. The students completed the questionnaire consisting of 15 general and 3 specific questions that queried both studio approaches and also personal questions such as age and gender. The students were asked to assess the following headings with 5 point Likert scale: the contributions of the design studio approaches to their creativity and self-confidence; their interaction with peers and instructor(s); their utilization of the design studio medium during class hours; and the impact of the design studio approaches to the jury assessments and final grades. It was accepted that while answering the questions, the participants reflected their real emotions and thoughts; responded to the questionnaire ambitiously, correctly and completely; and understood the words literally.

At the beginning of each semester, a directive was constituted about the studio rules and the predictions of the design studio approach that would be executed in that semester, and it was approved by all the instructors. The meetings with the instructors were held in 4-week periods in both fall and spring semesters to control if the instructors follow the directive of the applied design studio approach, to prevent possible education style differences between the instructors, and to share the experiences. In this study, the researcher assumed that the instructors did not make a significant mistake to affect the whole process.

The most important limitation of this study was that the comparisons were only made through the students' assessments, and the instructors were not included in the research due to the insufficient number of instructors to generalize the results. Besides, only third-year students participated in the design studios that were carried out with different approaches in different semesters. Therefore, another limitation of this 
study was that the students from other grades were not included in the comparisons. The problem-solving skills of the students varied depending on their semesters. It was predicted that the varied cognitive skills of the students could affect the results, especially in the independent design studio approach. Therefore, the study was conducted with third-grade students with the same cognitive skills.

\section{Participants}

This research was executed with the participation of 44 students (31 female, 13 male; the youngest age was 21; the oldest age was 29; the mean value was 22,9) from the Department of Interior Architecture and Environmental Design at a university in Istanbul.

Students who experienced the independent design studio approach were given the task of designing a medical centre within the scope of Design Studio III in the fall semester while within the scope of Design Studio IV; the students who experienced the controlled design studio approach were given the task of designing a boutique hotel in the spring semester.

The purposive sampling method was used in the election of the participants. In this study, which aims to compare two different approaches applied in architectural design studio education, third-year students who experienced both independent and controlled design studio approaches were chosen as participants.

\section{RESULTS OF THE EXPERIMENT}

The data obtained from the questionnaire were analysed in the IBM SPSS 24.0 package program. Initially, the reliability of the questionnaire was evaluated. Then, the Kolmogorov-Simirnov normality test was applied to the data. Since the normal distribution was achieved, Paired t-test was used for the difference analysis.

\section{Reliability Analysis of the Questionnaire}

Cronbach Alpha, Split, Parallel and Absolute Parallel (strict) tests are used to analyse the reliability of a questionnaire in general. Cronbach Alpha test results above $70 \%$ mean that the survey is successful. Besides, some researchers expect this value to be over $75 \%$. The fact that other reliability criteria are above $70 \%$ indicates that the internal consistency of the questionnaire is ensured, and inferences can be trusted (Özdamar, 2004). As can be seen in Table 1, the percentages indicated and expected to be at the end of all four tests met the confidence criterion. Hence, it was concluded that the sample results were consistent and reliable with highreliability values. As all of the reliability criteria were over $70 \%$, it was concluded that the survey was successful and consistent in itself, and the results would reflect the real values. 
Table 1. Results of the reliability analysis of the survey (Erçevik Sönmez, 2019)

\begin{tabular}{|c|c|}
\hline Criterions & Reliability Results of the Survey \\
\hline Cronbach Alpha & 0.825 \\
\hline Split & $0.824-0.826$ \\
\hline Parallel & 0.824 \\
\hline Strict & 0.825 \\
\hline
\end{tabular}

\section{Testing the Hypothesis}

It was tested whether there was a significant difference between the independent design studio approach (IDS) and the controlled design studio approach (CDS). The same dependent groups were in question since the same students evaluated both design studio approaches. Kolmogorov-Smirnov normality test was applied to find out which testing method to be used. Since the p-value of both design studio approaches for the questionnaire was $\mathrm{p}>0.05, \mathrm{H} 0$ hypothesis was accepted indicating that normal distribution was achieved. In this circumstance, Paired t-test was applied (Table 2).

Table 2. Paired t-test results (Erçevik Sönmez, 2019)

\begin{tabular}{|c|c|c|c|c|c|c|}
\hline & & Mean & $\mathrm{N}$ & $\begin{array}{l}\text { Std. } \\
\text { Dev. }\end{array}$ & $\begin{array}{c}\mathrm{t} \\
\text { statistics }\end{array}$ & $\mathrm{p}$ \\
\hline \multirow{2}{*}{$\begin{array}{l}\text { This experience enhanced my } \\
\text { creativity. }\end{array}$} & IDS & 2,7955 & 44 & 1,33955 & \multirow{2}{*}{-6.378} & \multirow{2}{*}{$0.000^{*}$} \\
\hline & CDS & 4,4773 & 44 & ,69846 & & \\
\hline \multirow{2}{*}{$\begin{array}{l}\text { This experience encouraged me to } \\
\text { produce new ideas. }\end{array}$} & IDS & 8182 & 4 & 1,20605 & \multirow{2}{*}{-7.942} & \multirow{2}{*}{$0.000^{*}$} \\
\hline & CDS & 4,5227 & 44 & ,66433 & & \\
\hline \multirow{2}{*}{ The design studio was dynamic. } & IDS & 2,0909 & 44 & 1,09583 & \multirow{2}{*}{-6.658} & \multirow{2}{*}{$0.001^{*}$} \\
\hline & CDS & 3,6136 & 44 & 1,12510 & & \\
\hline \multirow{2}{*}{$\begin{array}{l}\text { This experience led me to investigate } \\
\text { the sample designs. }\end{array}$} & IDS & 2,5682 & 44 & 1,37075 & \multirow{2}{*}{-5.813} & \multirow{2}{*}{$0.000^{*}$} \\
\hline & CDS & 4,0000 & 44 & ,83527 & & \\
\hline \multirow{2}{*}{$\begin{array}{l}\text { During the studio hours, I drew and } \\
\text { practiced with mock-ups in the design } \\
\text { studio medium. }\end{array}$} & IDS & 3,1591 & 44 & 1,27486 & \multirow[b]{2}{*}{-2.178} & \multirow[b]{2}{*}{$0.002^{*}$} \\
\hline & CDS & 3,6818 & 44 & ,95899 & & \\
\hline \multirow{2}{*}{$\begin{array}{l}\text { I had the knowledge of different design } \\
\text { ideas of my peers. }\end{array}$} & IDS & 2,6591 & 44 & 1,25648 & \multirow{2}{*}{-4.661} & \multirow{2}{*}{$0.026^{*}$} \\
\hline & CDS & 3,7500 & 44 & ,86603 & & \\
\hline \multirow{2}{*}{$\begin{array}{l}\text { I interacted with all the instructors, and } \\
\text { asked for comments. }\end{array}$} & IDS & 2,4091 & 44 & 1,33501 & \multirow{2}{*}{-2.985} & \multirow{2}{*}{$0.000^{*}$} \\
\hline & CDS & 2,9318 & 44 & ,97403 & & \\
\hline \multirow{2}{*}{$\begin{array}{l}\text { The instructor(s) provided sufficient } \\
\text { time to me for the critiques. }\end{array}$} & IDS & 1,6818 & 44 & 1,17677 & \multirow{2}{*}{-14.030} & \multirow{2}{*}{$0.001^{*}$} \\
\hline & CDS & 4,6364 & 44 & ,71823 & & \\
\hline \multirow{2}{*}{$\begin{array}{l}\text { I was confused by the critiques and } \\
\text { comments I've had in this experience. }\end{array}$} & IDS & 4,0909 & 44 & 1,23549 & \multirow{2}{*}{13.543} & \multirow{2}{*}{0.028} \\
\hline & CDS & 1,3636 & 44 & ,65026 & & \\
\hline \multirow{2}{*}{$\begin{array}{l}\text { This experience negatively affected my } \\
\text { end-of-term grade. }\end{array}$} & IDS & 3,9773 & 44 & 1,33797 & \multirow{2}{*}{11.076} & \multirow{2}{*}{$0.000^{*}$} \\
\hline & CDS & 1,5227 & 44 & ,66433 & & \\
\hline & IDS & 2,6364 & 44 & 1,20253 & -5529 & 000 \\
\hline medium. & CDS & 3,9545 & 44 & 1,01052 & & \\
\hline I did not need to continue studying on & IDS & 2,1136 & 44 & ,96968 & & \\
\hline $\begin{array}{l}\text { my design drafts ou } \\
\text { medium. }\end{array}$ & CDS & 3,2727 & 44 & 1,12815 & -4.900 & $0.000^{*}$ \\
\hline I felt emotionally strong during the jury & IDS & 1,8409 & 44 & 1,07710 & & \\
\hline assessments. & CDS & 4,4318 & 44 & ,75937 & 12 & 0. \\
\hline It was easy to follow & IDS & 1,9318 & 44 & 1,16933 & & \\
\hline & CDS & 4,5000 & 44 & ,76249 & & 0.00 \\
\hline This experience positively affected my & IDS & 2,1818 & 44 & 1,14674 & & $00^{-1}$ \\
\hline ability to think, criticize and design. & CDS & 4,2727 & 44 & ,89867 & & \\
\hline
\end{tabular}


* 0.05 significant level statistically significant difference

Significant differences were obtained in both stages of the experiment. The average values of the controlled design studio approach were higher, except for the statements "I was confused by the critiques and comments I've had in this experience" and "This experience negatively affected my end-of-term grade".

\section{Discussions}

Design studios are the basis of architectural education that aids students to develop their ability to research, think, criticize, interpret, design and present. Independent and controlled design studio approaches were both expected to enhance students' creativity and encourage them to produce new ideas. However, the independent design studio approach provided the opportunity to ask for comments and critiques from any of the instructors of that studio, to develop the design ideas and draft drawings all day long by practicing freely in the design studio medium, and to observe and criticize different design ideas of the peers in each studio day since the students freely scattered to the design studio medium. Therefore, the mean values of the independent design studio approach were predicted to be higher than the controlled design studio approach. Conversely, the mean values of the controlled design studio approach on enhancing the creativity of the students were higher than the independent design studio approach. In the independent design studio approach, the confusion of the students caused by the critiques and comments of different instructors, the reluctance of the students to practice in the studio medium all day long and to estrange from their design practices due to the studio meetings applied once a week might have negatively affected their courage for producing new design ideas.

It was predicted that the independent design studio was a dynamic approach while the controlled design studio was a static one. However, according to student assessments, the controlled design studio approach was more dynamic than the independent design studio approach. The inaccurate behaviours of the project coordinator and/or the instructors in the execution of the independent design studio approach, the challenges in the interaction between the students and the instructors, and also the defectiveness in the information exchange among students might have caused this approach not to be evaluated dynamically. Conversely, in the controlled studio approach, the fact that the interaction and the knowledge sharing of the instructor with the students was more intense and individual, that the instructor had high domination over all the design ideas within the group, and that the students also dominated on the design ideas of their group peers and generate new ones for them might have caused this approach to be evaluated dynamically.

The mean values of the controlled design studio approach regarding leading the students to investigate the sample designs were higher than the independent design studio approach. In the independent design 
studio approach, students might have remained incapable to analyse and interpret the comments of different instructors of that studio. Therefore, the investigations that students were expected to do to develop their original design ideas were probably negatively affected. Besides, the instructors might have deficiencies in exemplifying and providing resources to students and encouraging them to research. On the other hand, in the controlled design studio approach, the instructor might have had the opportunity to share their professional and academic experiences with the students and exemplify these within the group. Besides, the instructor was concerned with the students individually, and knew their deficiencies; so, informed them about the appropriate resources and the research methods to overcome those deficiencies. Therefore, in the controlled studio approach, the weekly individual desk critiques with the instructor created a compulsory impulse for the students to investigate their deficiencies in design and to project learned ones to their design. These results confirm the significance of effective communication between the instructors and the students in architectural design education, and the inevitability of desk critiques for pursuing the design processes of the students (Uluoğlu, 2000; Kurt, 2009; Oh et.al, 2013).

In the independent design studio approach, it was predicted that students would have enough time to draw and practice with mock-ups in the design studio medium all day long and to develop their design drafts by discussing their ideas several times with any of the instructors. On the other hand, in the controlled design studio approach it was envisaged that two half-day studio meetings were not sufficient to practice in the studio medium and that after individual desk critiques with the instructor, students would not have enough time to revise their mock-ups and drawings in the studio medium and get some critiques again. However, contrary to the prediction, in the controlled design studio approach, the mean values regarding drawing and practicing with mockups in the design studio medium during studio hours were higher than the independent design studio approach.

In the independent design studio approach, it was accepted that the students would not be divided into groups and that all of the peers would draw and practice together in interaction. Therefore, the students were expected to be informed of the different design ideas of their peers and to contribute with their criticism. The controlled design studio approach proceeded with the individual desk critiques in a group of 12 to 15 students, supervised by an instructor, and students were not expected to be informed of the design ideas of their peers in other groups. However, in the controlled design studio approach, the mean values regarding knowing different design ideas of the peers were higher than the independent design studio approach. In the independent design studio approach, students were probably not concerned with other projects of their peers designed within the studio medium while trying to advance their design drafts by interpreting different ideas from the different 
instructors. Since they concentrated on their design drafts, they might have missed the critiques of other projects of their peers. Physical conditions might have also been an obstacle. In a controlled design studio approach, a group of 12 to 15 students and an instructor gathered around a table, and desk critiques and evaluations were done within the group. Therefore, it was physically adequate for the students to follow the desk critiques and to generate ideas within their group or the others. This result supports the study conducted by Afacan (2012) which emphasized that working within a group improved the relationship of the students with peers.

In the independent design studio approach, students were free to get critiques from any of the instructors. So, they were expected to interact with all the instructors and to ask for comments. On the other hand, in the controlled design studio approach, students were not expected to interact with any of the instructors except their group instructor. However, in the controlled design studio approach, the mean values regarding interaction with all the instructors, and asking for comments from them were higher than the independent design studio approach. In the independent design studio approach, the challenges in the physical conditions of the studio medium such as the division of the students into two or more studios due to the inadequate dimensions of the studio mediums, the situations that prevent the dominance of the whole studio medium such as columns, etc.; the reluctance of the student to ask for critiques from all the instructors; and the problems that occurred during the execution of the approach might have caused negative assessments. The controlled design studio approach was executed as two half days (4 + 5 hours) per week; and it was predicted that the group instructor might not be able to allocate sufficient time for individual desk critiques to all students within the group in a half-day studio meeting. On the other hand, in the independent design studio approach, the students had the opportunity to draw and practice in the studio medium all day long and to get critiques from different instructors. Conversely, in the controlled design studio approach, the mean values regarding providing sufficient time by the instructor for the critiques were higher than the independent design studio approach.

In the independent design studio approach, analysing different interpretations could be a difficult process for students and confusions by the critiques and comments of different instructors might have been experienced. On the other hand, in the controlled design studio approach, understanding, analysing and executing the comments and the critiques of the same instructor in every studio meeting was not a confusing process. As predicted, in the controlled design studio approach, the mean values regarding confusion by the critiques and comments of the instructors were higher than the independent design studio approach. In the independent design studio approach, the mean values regarding the negative effects on end-of-term grades were higher than the controlled design studio approach. In the independent design studio 
approach, due to the lack of the individual desk critiques between the instructor and the students, the students might not be able to understand the deficiencies in their design drafts, and improve them. Also, they might not be able to evaluate the critiques of the instructors and might have made incorrect or inadequate design decisions. Since the instructors did not interact with the students individually, the students believed that the instructors did not have any opinions about their studio performances. Thus, those interpretations can be cited as a negative evaluation of the independent design studio approach in terms of the end-of-term grade. In the controlled design studio approach, the fact that the instructor was able to criticize and improve the deficiencies in design drafts of the students individually; and that the instructors had opinions about the studio performances of every student they supervised, might have caused this experience to be evaluated positively in terms of the end-of-term grade. Herein, this result reconfirms the significance of desk critiques and group critiques which are the essence of the relation between the instructor and students (Oh et.al, 2013).

The independent design studio approach, since it was applied as full-time 9 hours a week session, allowed the student to study effectively in a design studio medium and to get critiques from different instructors at any time. Conversely, in the controlled studio approach, as it was executed as two half days $(4+5$ hours) per week and the students' obligation to get individual critiques from their instructor and to follow the critiques of the others, there might not have been sufficient time to study effectively in the design studio medium. However, the mean values of the controlled design studio approach regarding studying effectively in the design studio medium were higher than the independent design studio approach. The negative evaluations, contrary to the prediction for the independent design studio approach may have originated from physical inadequacies in the studio medium such as the lack of a sufficient number of desks or drafting boards and the lack of electrical outlets for computerized practices, the inabilities in executing the approach and in encouraging students to study in the studio medium, and the reluctances of the students to practice effectively in the studio medium. Moreover, in the controlled design studio approach, the dominance of the instructors to the group of students they supervised, their encouragement of students to study effectively in the studio medium, and their trace and evaluation of design drafts individually may have caused positive evaluations.

It was predicted that in the independent design studio approach students had sufficient time to improve their design drafts in the studio medium so that they would not need to continue studying on their drafts when they were out of the studio medium. However, the mean values of the controlled studio approach regarding students not studying on their design drafts outside the studio medium were higher than the independent design studio approach. Therefore, design studio hours of full-day in a week session executed in the independent design studio 
approach did not eliminate the necessity for students to practice outside the studio medium.

In the controlled design studio approach, the presence of a group instructor who tracked, guided, and criticized the students for 14 weeks, supported the students schematically and emotionally. Therefore, it was predicted that students would feel emotionally protected, supported and strong during the jury assessments. Conversely, the independent design studio approach, where the students were not supervised by a group instructor, may have caused the students to feel emotionally unsupported. As predicted, the mean values of the controlled design studio approach regarding students feeling emotionally strong during the jury assessments were higher than the independent design studio approach. This result reconfirms the significance of an effective relationship between the studio instructors and the students in design studio education (Uluoğlu, 2000).

The mean values of the controlled design studio approach regarding the ease of following the critiques and comments were higher than the independent design studio approach. As mentioned before, in the independent design studio approach, the critiques received from different instructors might have caused confusion and difficulties might have been experienced in following the given critiques.

It was predicted that the independent design studio approach positively affected the ability of the students to think, criticize and design. However, contrary to the prediction, the mean values of the controlled design studio approach were higher than the independent design studio approach.

The discussions mentioned in details are summarized in the table below:

Table 3. The comparisons of the two design studio approaches (Erçevik Sönmez, 2020)

\begin{tabular}{|c|c|c|}
\hline The predictions & $\begin{array}{c}\text { The controlled design studio } \\
\text { approach }\end{array}$ & $\begin{array}{c}\text { The independent design studio } \\
\text { approach }\end{array}$ \\
\hline $\begin{array}{l}\text { Enhancing the } \\
\text { creativity of the } \\
\text { students }\end{array}$ & Enhanced more & $\begin{array}{l}\text { Enhanced less } \\
\text { - Due to the confusion of the } \\
\text { students caused by the } \\
\text { critiques of different } \\
\text { instructors; } \\
\text { - Due to the reluctance of the } \\
\text { students to practice in the } \\
\text { studio medium all day } \\
\text { long; } \\
\text { Due to the alienation from } \\
\text { the design practices since } \\
\text { the studio meetings } \\
\text { applied once a week; }\end{array}$ \\
\hline $\begin{array}{l}\text { Encouraging } \\
\text { students to } \\
\text { produce new } \\
\text { ideas }\end{array}$ & Encouraged more & Encouraged less \\
\hline
\end{tabular}




\begin{tabular}{|c|c|c|}
\hline $\begin{array}{l}\text { Dynamic vs. } \\
\text { Static }\end{array}$ & $\begin{array}{l}\text { More dynamic } \\
\text { - Due to the intense and } \\
\text { individual interaction } \\
\text { between the instructor } \\
\text { and the students; } \\
\text { - Due to high domination } \\
\text { of the instructor within } \\
\text { the group; } \\
\text { Due to the students' } \\
\text { knowing on the design } \\
\text { ideas of their group } \\
\text { peers and generate new } \\
\text { ones for them; }\end{array}$ & $\begin{array}{l}\text { Less dynamic } \\
\text { - Due to the inaccurate } \\
\text { behaviours of the project } \\
\text { coordinator and/or the } \\
\text { instructors in the } \\
\text { execution of the studio } \\
\text { approach; } \\
\text { Due to the challenges in the } \\
\text { interaction between the } \\
\text { students and the } \\
\text { instructors; } \\
\text { Due to the defectiveness in } \\
\text { the information exchange } \\
\text { among students, }\end{array}$ \\
\hline $\begin{array}{l}\text { Leading students } \\
\text { to investigate } \\
\text { the sample } \\
\text { designs }\end{array}$ & $\begin{array}{l}\text { More investigation } \\
\text { - The instructor informed } \\
\text { the students individually } \\
\text { about the appropriate } \\
\text { resources. } \\
\text { - The weekly individual } \\
\text { desk critiques created a } \\
\text { compulsory impulse to } \\
\text { investigate the } \\
\text { deficiencies of the } \\
\text { students in the design. }\end{array}$ & $\begin{array}{l}\text { Less investigation } \\
\text { - Due to the incapability of } \\
\text { the students to analyse and } \\
\text { interpret the comments of } \\
\text { different instructors; } \\
\text { - Due to the deficiencies of } \\
\text { the instructors in } \\
\text { exemplifying and } \\
\text { providing resources to } \\
\text { students and encouraging } \\
\text { them to research; }\end{array}$ \\
\hline $\begin{array}{l}\text { Drawing and } \\
\text { practicing in the } \\
\text { studio medium }\end{array}$ & More effective & Less effective \\
\hline $\begin{array}{l}\text { The knowledge } \\
\text { of different } \\
\text { design ideas of } \\
\text { their peers }\end{array}$ & $\begin{array}{l}\text { More knowledge about the } \\
\text { peers } \\
\text { - } \quad \text { Physically adequate for } \\
\text { the students to follow the } \\
\text { desk critiques; }\end{array}$ & $\begin{array}{l}\text { Less knowledge about the } \\
\text { peers } \\
\text { - The students might have } \\
\text { missed the critiques of } \\
\text { their peers while trying to } \\
\text { advance their design drafts } \\
\text { by interpreting different } \\
\text { ideas from the different } \\
\text { instructors. }\end{array}$ \\
\hline $\begin{array}{l}\text { Interaction with } \\
\text { all the } \\
\text { instructors }\end{array}$ & More interaction & $\begin{array}{l}\text { Less interaction } \\
\text { - Due to the challenges in the } \\
\text { physical conditions of the } \\
\text { studio medium; } \\
\text { Due to the reluctance of the } \\
\text { students to ask for } \\
\text { critiques from all the } \\
\text { instructors; } \\
\text { Due to the problems that } \\
\text { occurred during the } \\
\text { execution of the approach; }\end{array}$ \\
\hline $\begin{array}{l}\text { Sufficient and } \\
\text { equal time to all } \\
\text { students for the } \\
\text { critiques }\end{array}$ & $\begin{array}{c}\text { More sufficient and equal } \\
\text { time }\end{array}$ & Less sufficient and equal time \\
\hline $\begin{array}{l}\text { Confusing } \\
\text { critiques and } \\
\text { comments }\end{array}$ & Less confusing process & More confusing process \\
\hline
\end{tabular}




\begin{tabular}{|c|c|c|}
\hline & $\begin{array}{l}\text { Due to the critiques of } \\
\text { the same instructor in } \\
\text { every studio meeting; }\end{array}$ & $\begin{array}{l}\text { Due to the different } \\
\text { critiques of the different } \\
\text { instructors; }\end{array}$ \\
\hline $\begin{array}{l}\text { The end-of-term } \\
\text { grade }\end{array}$ & $\begin{array}{l}\text { Affected Positively } \\
\text { - Due to the opinions of } \\
\text { the instructors about the } \\
\text { studio performances of } \\
\text { every student they } \\
\text { supervised; }\end{array}$ & $\begin{array}{l}\text { Affected Negatively } \\
\text { - The students believed that } \\
\text { the instructors did not } \\
\text { have any opinions about } \\
\text { their studio performances. }\end{array}$ \\
\hline $\begin{array}{l}\text { Studied } \\
\text { effectively in the } \\
\text { design studio } \\
\text { medium }\end{array}$ & $\begin{array}{l}\text { More effective } \\
\text { - Due to the dominance } \\
\text { and the encouragement } \\
\text { of the group instructors; }\end{array}$ & $\begin{array}{l}\text { Less effective } \\
\text { - Due to the physical } \\
\text { inadequacies in the studio } \\
\text { medium; } \\
\text { - Due to the inabilities in } \\
\text { executing the approach; } \\
\text { Due to the inabilities in } \\
\text { encouraging students to } \\
\text { study in the studio } \\
\text { medium; } \\
\text { Due to the reluctances of } \\
\text { the students; }\end{array}$ \\
\hline $\begin{array}{l}\text { The necessity to } \\
\text { practice outside } \\
\text { the studio } \\
\text { medium }\end{array}$ & $\begin{array}{l}\text { The approach did not } \\
\text { eliminate. }\end{array}$ & $\begin{array}{c}\text { The approach did not } \\
\text { eliminate. }\end{array}$ \\
\hline Jury assessments & $\begin{array}{l}\text { Felt emotionally } \\
\text { protected, supported } \\
\text { and strong } \\
\text { - } \quad \begin{array}{l}\text { Due to the presence of a } \\
\text { group instructor; }\end{array}\end{array}$ & $\begin{array}{l}\text { Felt emotionally unsupported } \\
\text { - Due to the lack of a } \\
\text { supervision by a group } \\
\text { instructor; }\end{array}$ \\
\hline $\begin{array}{l}\text { Following up the } \\
\text { critiques and } \\
\text { comments }\end{array}$ & Easier & $\begin{array}{l}\text { Not easier } \\
\text { - Confusion and difficulties } \\
\text { due to the critiques } \\
\text { received from different } \\
\text { instructors; }\end{array}$ \\
\hline $\begin{array}{l}\text { Contribution to } \\
\text { the students' } \\
\text { ability to think, } \\
\text { criticize and } \\
\text { design }\end{array}$ & Contributed more & Contributed less \\
\hline
\end{tabular}

In this research, questionnaires were not conducted with the instructors due to the insufficient numbers for the statistical analysis and generalizations. The opinions of the instructors about the design studio approach and the process were obtained from the meeting records repeated in four-week periods. The positive and negative opinions of the instructors about the process of the independent design studio approach are as follows:

"A dreamy studio medium has been created. Although students complain about the full day studio, the brainstorming was executed at the level that this approach intended. ... Many of the students 
never worked in the studio. They don't know how to benefit from the studio medium. They didn't present their work and didn't get individual critiques from the instructors. The student, who presented his/her products or drawings in the morning session, disappeared in the afternoon session." USS

"We created a creative and interactive studio medium. It was different from the readymade system. The student tried to interpret various ideas and evaluations, and reflect them on his/her designs.

... Giving critiques to many students was a tiring process. Especially at the end of the day, we could not find the power to guide the students." TBD

"The students helped each other's designs. Actually, they united against the instructors. We can say that a strong collaboration occurred. ... We could not understand whether the project was designed by the student or he/she received any professional help since we couldn't observe the students in detail. We couldn't understand their skills and design abilities. ... In fact, we graded students impartially. In the juries, we only graded what the students drew and presented. The subjective judgments did not interfere." $D M$

"We knew more or less about all the projects; and contributed to their development. ... We were confused about whom we gave critiques, and what kind of corrections we made. Also, giving critiques to design later on the comments of an instructor caused conflicts and disputes among the instructors." KOA

The positive and negative opinions of the instructors about the process of the controlled design studio approach are as follows:

"The interaction between the groups was weak. Some cooperation among the students within the group was done; but as for me they were not sufficient for brainstorming. ... Some students from the other groups came to ask questions and ask for critiques. Working within a group did not prevent the students to ask for critiques from the other instructors beyond his/her group supervisor. This was very good; but the time was limited. It did not suffice... It was nice to have a close relationship with the students and pay attention to them individually. The master-apprentice relationship continued. To guide the students to complete their deficiencies was more ease. For instance, I could bring sourcebooks and drawings to show within the group or lend them to someone." US

"Some students do not work in the studio medium in any way, but some are more willing to do so. Most of the students anticipated readymade answers to their design problems. ... It was a less tiring process to criticize a certain group of students. But we could not know what the students in the adjacent studio were doing. If it hadn't been for the periodical meetings among the instructors, we would not also know what the instructors did." TBD 
"As an instructor, I know all my students, their projects, and their ability to design and draw. I could understand their skills and design abilities. I could know what and how much he/she could do. Thus, you can develop a specific approach for each student. ... Of course, being with students within a group affected the grade I gave at the end of the semester because I knew all the students within my group, and also their ability to design. The subjective judgments can be involved in the assessment." DM

"It was difficult to provide equal time for all students. The studio hours were extended. I could not give sufficient critiques to some of my students. ... Practicing with the students for two days caused the project to progress faster. The student did not alienate from the design practices, and so the instructor did not. Their concentration was high. To follow up on the student and their progress was easy." KOA

All the results described above in detail demonstrate that the negative assessments of students about the independent design studio approach were higher than the controlled design studio approach. As verified with the statistical comparisons of both approaches, the controlled design studio approach was utilized as more positive. The research hypothesized that in architectural design education, the independent design studio approach is more successful than the controlled studio approach. The hypothesis of the research is not confirmed. Even though the independent design studio approach was predicted to be a more successful, creative, collaborative and experimental approach and a more suitable studio medium for studying, students were not ready for it. This result supports the study conducted by Ciravoğlu (2014), in which a new teaching method of students developing their projects with different ideas of different instructors was introduced. But distinctly, in this research the questionnaires were conducted only with students due to the insufficient number of instructors for statistical analysis. More comprehensive research where the opinions of instructors for both design approaches will be evaluated with a survey to generalize and compare the findings with this research is recommended.

\section{CONCLUSIONS}

In this study, an experiment was conducted that compared two different educational approaches -independent and controlled design studio approaches- executed in architectural design studio education via students' assessments. In the Fall Semester, a questionnaire that evaluated the independent design studio approach was conducted to 44 third-year students while in the Spring Semester, the same questionnaire was conducted to the same students to evaluate the controlled design studio experience. The key points of this research are summarized below: - The controlled design studio approach is more successful than the independent studio approach. 
- In the independent studio approach, the instructors did not provide sufficient and equal time to all the students for the critiques; therefore, the interaction between the instructors and the students were weak. Following up the critiques and comments of different instructors was a difficult process for the students, and hence, confusions were experienced. Studying and practicing full-day in the studio medium did not eliminate the necessity for students to continue studying outside the studio medium. Students thought that the independent studio approach negatively affected their end-of-term grade and they felt emotionally defenceless and unsupported during the jury assessments. The independent studio experience did not contribute to the students' ability to think, criticize and design.

- The controlled design studio was a dynamic approach that enhanced students' creativity more than the independent design studio approach and led them to investigate the sample designs, projects and materials more. It encouraged students to produce new ideas. Students studied effectively in the design studio medium, and knew different design ideas of their peers. Following up the critiques and comments of the instructor were ease since the students studied with the same instructor over a semester; and hence, confusions were not experienced and students could concentrate more on their designs. The group instructor provided sufficient time to all students for the critiques. Studying and practicing twice a week in the studio medium did not eliminate the necessity for students to continue studying outside the studio medium. Students did not think that the controlled studio approach negatively affected their end-of-term grade, and they felt emotionally strong and supported during the jury assessments. The controlled studio experience contributed to the students' ability to think, criticize and design.

During the execution of the independent and controlled design studio approaches, some deficiencies related to the approaches were identified; and the reasons for these deficiencies were determined by the data analysis and the opinions of the instructors. The deficiencies and their reasons for the independent design studio approach are listed below:

- $\quad$ The confusion of the students due to the critiques and comments of different instructors;

- Not practicing efficiently in the studio medium due to the reluctance of the students to practice in the studio medium all day long, and the physical inadequacies in the studio medium such as the lack of a sufficient number of desks or drafting boards;

- The alienation from the design practices and inability to concentrate due to the execution of studio meetings once a week, and the lack of high domination of a group instructor;

- $\quad$ The problems in the interaction between the students and the instructors due to the lack of an individual and intense relationship between them, the reluctance of the students to ask for critiques from 
some of the instructors, and the requests of the students to interact with a group instructor;

- $\quad$ The problems in the interaction among the students due to the lack of desk critiques where an exchange of ideas within the group is executed, and the high concentration on their designs and disregarding of the projects of their peers designed within the studio medium while interpreting different ideas from the different instructors;

- $\quad$ The difficulty in following up the critiques due to the confusion of the students caused by the various comments of different instructors;

- $\quad$ The problems during the execution of the approach due to the disagreements between the instructors, and not having understood the approach sufficiently and correctly;

- $\quad$ The decrease in the students' desire to generate new ideas due to the confusion of the students caused by the critiques of different instructors; the lack of the compulsory impulse of weekly individual desk critiques, and the non-necessity of getting critiques from any of the instructors;

- $\quad$ The negative judgments about the final grade due to the lack of supervision by a group instructor, the feeling of being emotionally unsupported, and the in cognizance of the instructors about the design abilities and the studio performances of the students;

The deficiencies and their reasons for the controlled design studio approach are listed below:

- Not practicing efficiently in the studio medium due to the insufficient time to practice in the studio caused by studio hours executed as two half days ( $4+5$ hours) per week, and the physical inadequacies in the studio medium such as the lack of a sufficient number of desks or drafting boards;

- Insufficient time for the critiques due to the studio hours executed as two half days ( $4+5$ hours);

- $\quad$ The decrease in the students' desire to generate new ideas due to the lack of sufficient brainstorming, the desire of the students to imitate the instructor, and the reluctance to take initiative and responsibility in design;

- $\quad$ The problems during the execution of the approach due to the disagreements between the instructors, and not having understood the approach sufficiently and correctly;

- $\quad$ The unawareness of the products of the other groups of students due to the critique sessions of the supervisor within a group of 12-15 students, having a chance to analyse all the products only in juries, and the lack of interaction among the design groups.

In line with the general conclusions of the study, the following suggestions were listed for the instructors:

- The assessments of the students should be taken into consideration when determining the design studio approach. 
- $\quad$ Design studios should be designed through dynamic approaches that enhance the creativity of the students, encourage them to produce new ideas and direct them to research.

- Students should be encouraged to produce in the studio medium.

- $\quad$ Physical conditions such as the dimensions of the studio medium, the number of the drawing tables, the number of the electric sockets, daylight, illumination, natural ventilation and noise control must be sufficient so that students can study comfortably in the studio medium.

- The meetings with the instructors should be arranged twice a week to keep students under control of instructors, to ensure that the students manage the design processes appropriately, and to prevent the reluctance of the students in the design studio.

- The arrangement of studio hours for half a day should not be accepted as an obstacle for students to study in the studio medium.

- $\quad$ Supervision by an instructor over a semester is recommended in terms of the individual tracing of the instructor to all the students, and the willingness of the students for the design studio.

- Necessary precautions should be taken to eliminate the confusion, lack of interest, the feeling of insecurity and lack of support of the students in some studio approaches where students can get critiques from more than one instructor, or where the instructors alternate for giving critiques.

- $\quad$ The weekly hours of the design studio and the quality of studio work do not reduce the extracurricular workload of students.

In this research, two different educational approaches -independent and controlled design studio approaches- executed in architectural design studio education was compared via third-year design studio students' assessments. Furthermore, the results of this study may change when the instructors' opinions for both design approaches are discussed. This discussion can be diversified with the comparisons between horizontal and vertical design studio approaches and/or between weekly desk critiques and monthly jury sessions approaches executed in graduation studios. This study on third-year design studio students' assessments can also be adapted to different studio grades and a greater number of students. Consequently, this study can be a sample for the other researches on similar subjects.

\section{CONFLICT OF INTEREST}

The author declared that there is no conflict of interest in this study.

\section{FINANCIAL DISCLOSURE}

The author declared that this study has received no financial support.

\section{ETHICS COMMITTEE APPROVAL}

In this research, the necessary permissions were obtained from the relevant ethics committee of the university before the experiment. 


\section{LEGAL PUBLIC/PRIVATE PERMISSIONS}

In this research, the necessary permissions were obtained from the relevant participants (individuals, institutions and organizations) during the survey, in-depth interview and observation.

\section{REFERENCES}

Adıgüzel Özbek D., Melikoğlu Eke, A. S., Yücesan, E. \& Ozar, B. (2018). Vertical design studio experience in interior architecture education, Online Journal of Art and Design, 6(2), 159-175.

Afacan, Y. (2012). Investigating the effects of group working in studying interior architecture, Procedia Social and Behavioral Sciences, 51, 506511.

Akalın, A. \& Sezal, İ. (2009). The importance of conceptual and concrete modelling in architectural design education, The International Journal of Art and Design Education (JADE), 28(1), 14-24.

Ciravoğlu, A. (2003). Mimari tasarım eğitiminde formel ve enformel çalışmalar üzerine, yapı [About the formal and informal studies in architectural design education], Yapl, 257, 43-47.

Ciravoğlu, A. (2014). Notes on architectural education: an experimental approach to design studio, Procedia Social and Behavioral Sciences, 152, 7-12.

Demirbaş, O. O. \& Demirkan, H. (2003). Focus on architectural design process through learning styles, Design Studies, 24(5), 437-456.

Demirbaş, 0. 0. \& Demirkan, H. (2007). Learning styles of design students and the relationship of academic performance and gender in design education, Learning and Instruction, 17(3), 345-359.

Demirkan, H. \& Afacan, Y. (2012). Assessing creativity in design education: Analysis of creativity factors in the first-year design studio, Design Studies, 33(3), 262-278.

Ketizmen, G. (2003). Mimari tasarım stüdyosunda çalışma yöntemleri: Anadolu Üniversitesi mimarlık bölümü örneği, [Study methods in architectural design studio: The example of Anadolu University department of architecture], EgeMimarlık, 3(47), 32-34.

Kurt, S. (2009). An analytic study on the traditional studio environments and the use of the constructivist studio in the architectural design education, Procedia Social and Behavioral Sciences, 1(1), 401-408.

Kurt, S. (2011). Use of constructivist approach in architectural education, Procedia Social and Behavioral Sciences, 15, 3980-3988.

Kvan, T. \& Yunyan, J. (2005). Students' learning styles and their correlation with performance in architectural design studio, Design Studies, 26(1), 19-34.

Mutlu Danacl, H. (2015). Creativity and knowledge in architectural education, Procedia Social and Behavioral Sciences, 174, 1309-1312.

Nik Lukman Nik Ibrahim \& Uteberta, N. (2011). Learning in architecture design studio, Procedia Social and Behavioral Sciences, 60, 30-35. 
Oh, Y., Ishizaki, S., Gross, M. D. \& Yi-Luen Do, E. (2013). A theoretical framework of design critiquing in architecture studios, Design Studies, 34(3), 302-325.

Önal, G. K. \& Turgut, H. (2017). Cultural schema and design activity in an architectural design studio, Frontiers of Architectural Research, 6(2), 183203.

Özdamar, K. (2004). Paket Programlar ile Ístatistiksel Veri Analizi [Statistical Data Analysis with Package Programs]. Kaan Kitabevi.

Paker Kahvecioğlu, N. (2007). Architectural design studio organization and creativity, ITU A/Z, 4(2), 6-26.

Reffat, R. (2007). Revitalizing architectural design studio teaching using ICT: Reflections on practical implementations, International Journal of Education and Development Using Information and Communication Technology (IJEDICT), 3(1), 39-53.

Uluoğlu, B. (2000). Design knowledge communicated in studio critiques, Design Studies, 21(1), 33-58.

Ulusoy, Z. (1999). To design versus to understand design: The role of graphic representations and verbal expressions, Design Studies, 20(2), 123-130.

Youssef, K. A. (2014). Horizontal design studio versus vertical design studio: A tale of two architecture schools, $7^{\text {th }}$ International Conference of Education, Research and Innovation, 17-19 November 2014, pp. 50245034, Seville, Spain.

Wu, Y., Lin, Y.-A., Wen, M.-H., Perng, Y.-H. \& Hsu, I.- T. (2016). Design, analysis and user acceptance of architectural design education in learning system based on knowledge management theory, Eurasia Journal of Mathematics, Science \& Technology Education, 12(11), 2835-2849.

Verma, N. (1997). Design theory education: How useful is previous design experience?, Design Studies, 18(1), 89-99.

\section{Resume}

Begüm Erçevik Sönmez is an Assistant Professor in the Faculty of Architecture at Yeditepe University. She received her Ph.D. degree in 2016, her MSc degree in 2008, and her B.Arch in 2005 in Architecture from Ylldiz Technical University. Her research interests focus on environmental perception and cognition, built environment, spatial analysis and planning, and interior design. 